\title{
Determinant Factors of Sensory in Creating Autism Learning Environment
}

\author{
Roslinda Ghazali', Siti Rasidah Md Sakip 2, Ismail Samsuddin ${ }^{3}$, Heba Samra4 \\ 1 Department of Post-graduate, ${ }^{2}$ Department of Landscape Architecture, ${ }^{3}$ Department of Architecture, \\ Faculty of Architecture, Planning \& Surveying, \\ Universiti Teknologi MARA Perak Branch, Seri Iskandar Campus, 32610, Perak, Malaysia. \\ ${ }^{2}$ Green Safe Cities Research Group, Universiti Teknologi MARA, Shah Alam Campus,40450, Selangor, Malaysia. \\ ${ }^{4}$ Faculty of Fine Arts, Helwan University Cairo - Zamalek, 4 Mohamed Thakeb. St Zamalek, Cairo, Egypt. \\ lindakeruing@gmail.com, sitir704@perak.uitm.edu.my, \\ ismai587@perak.uitm.edu.my, heba_samra2009@yahoo.com \\ Tel: 0135185148
}

\begin{abstract}
Children with Autism Spectrum Disorder (ASD) have difficulty sitting still, focusing, and attending the task. Creating a sensory environment would promote a conducive environment for them. Sensory sensitivity, sensory stimulation, sensory design, and physical learning environment are the key concepts contributing to the autism environment. The study goal is to explore the design criteria for creating a conducive environment for autism. This article is to examine the reliability and validity of the four main constructs. This is important to ensure the quality of achieving the data. The study's significance is to provide a guideline during the design stage and improve the autism learning environment.
\end{abstract}

Keywords: Autism Spectrum Disorder; Principal Component Analysis, Autism Environment.

eISSN: 2398-42870 2021. The Authors. Published for AMER ABRA CE-Bs by e-International Publishing House, Ltd.. UK. This is an open access article under the CC BYNC-ND license (http://creativecommons.org/licenses/by-nc-nd/4.0/). Peer-review under responsibility of AMER (Association of Malaysian Environment-Behaviour Researchers), ABRA (Association of Behavioural Researchers on Asians/Africans/Arabians) and cE-Bs (Centre for Environment-Behaviour Studies), Faculty of Architecture, Planning \& Surveying, Universiti Teknologi MARA, Malaysia.

DOI: https://doi.org/10.21834/ebpj.v6i16.2696

\subsection{Introduction}

Autism Spectrum Disorder (ASD) is a complex developmental disorder that caused by brain damage, disrupting communications, behaviour, social skills, sensory, movement (movement of differences), and learning (Safrilia, 2017; Martins et al., 2015). The increasing population among autistic gives challenges to the family, society, education and nation (Razak, 2014). There is no cure for ASD; however, behavioural interventions and coordinated therapy can remedy and significantly improve specific symptoms (AltenmüllerLewis, 2017). The learning environment has become significant because research has proven that educational facilities' quality affects learning outcomes and the individuals within the building (Nazri \& Ismail, 2016). To enhance the development of children with autism, they stressed that it is essential to ensure that the building is effective, convenient, fit and feasible for all children to use, especially for children with autism (Martin, 2014). Suppose classrooms and learning environments not designed to accommodate students with developmental disabilities. In that case, autistic assumes that they will not learn these essential skills and may struggle to live in our society (Kanakri, 2017a). Therefore, Goodyear (2014) suggested that architects design with the basic in mind to minimize the sensory input that can overwhelm autistic children to learn more efficiently and develop with less stress. This article is to explore design criteria for creating a conducive learning environment comprised of sensory sensitivity, sensory stimulation, sensory design, and physical

eISSN: 2398-42870 2021. The Authors. Published for AMER ABRA cE-Bs by e-International Publishing House, Ltd., UK. This is an open access article under the CC BYNC-ND license (http://creativecommons.org/licenses/by-nc-nd/4.0/). Peer-review under responsibility of AMER (Association of Malaysian Environment-Behaviour Researchers), ABRA (Association of Behavioural Researchers on Asians/Africans/Arabians) and cE-Bs (Centre for Environment-Behaviour Studies), Faculty of Architecture, Planning \& Surveying, Universiti Teknologi MARA, Malaysia.

DOI: https://doi.org/10.21834/ebpj.v6i16.2696 
learning environment. This is important to ensure the quality of achieving the data. The study's significance is to provide a guideline during the design stage and improve the autism learning environment; hence the essential features are attributed to a conducive learning environment.

\subsection{Literature Review}

Autism Spectrum Disorders (ASD) has occurred in every nation of the world. In the United States, the prevalence of autism has been increasing in the last 40 years (Samadi \& McConkey, 2011). While in Malaysia, the number has been rising at 3\% per year (Mansor, 2016; Chiam, 2016; Zuljadan, 2017). The Ministry of Health in 2004 found that autism prevalence rates were 1 case for 600 births, with an estimated 13,333 children aged 15 and under are having autism in the country. However, the prevalence rate is closer such as 1 in 68 in the US and 1 in 100 in the UK (Chiam, 2016). The phenomena have an impact on the country, community, and family. The increasing rate is also a great challenge for the education system. According to Kanakri (2017b), the environment is essential to the treatment of autism because it influenced behaviour and suggested that architects and designers should modify the environment for children with autism.

Children with Autism Spectrum Disorder (ASD) have difficulty sitting still, focusing, and attending to the task. Creating a sensory environment would promote a conducive environment for them. Sensory sensitivity, sensory stimulation, sensory design, and physical learning environment are the main key concepts contributing to the autism environment. The first key concept is Sensory Sensitivity, relating information about how autistic responsiveness in the learning environment. There are seven components related to sensory sensitivity: sight, sound, smell, taste, touch, proprioception and vestibular. Sensory sensitivity has occurred in two common sensory patterns - hyper-sensitive and hypo-sensitive Children with hyper-sensitive and hypo-sensitive can be easily overwhelmed with the disturbing environment (Ghazali et al., 2019).

The second key concept is Sensory Stimulation related to unusual responses that stimulate autistic children in the environment. Sensory stimulation is related to five components - acoustic, colour, smell, lighting, and visual. Autistic may experience a completely different set of responses to a given stimulus than children who do not have autism (Ghazali et al., 2019). The learning environment setting should consider the sensory issues, reduce sensory stimulation, and make attending school an enjoyable, pleasurable experience and a learning place without distractions (Hebert, 2003; Beaver, 2006; Barrett et al., 2015).

The third key concept is Sensory Design relating to how space feels, sounds, looks, smells and affecting one or more of the seven senses, which can have an overwhelming effect on an autistic individual (Ghazali, Md. Sakip, et al., 2019). There are seven components - acoustic, spatial sequencing, compartmentation, transition zone, sensory zoning, safety, and security. When designing for autistic, it is essential to know and understand the autistic environment because not all children are affected in the same way or the same range (Scott, 2009). The composition of sensory stimuli in the built environments encourages the quality of life and experience for occupants. Architecture on occupants can be better through sensory design for a healthier mind and body (Osci, 2014).

The final key concept is Physical Learning Environment-related, the environment that affects children's learning processes and supports the well-being and education environment of autistic children. It consists of building scale, accessibility, wayfinding, toilet provision, window, ventilation and heating, threshold, legibility, and furniture. A study done by Shaari \& Ahmad (2016) proved a link between the physical learning environment and children's school readiness. Therefore, that environment can no longer ignore the importance of the physical learning environment. They suggested that a quality and adequately designed physical learning environment will boost children's development and education and contribute to improved school readiness among children and a better education system.

\subsection{Methodology}

This study is a quantitative approach in nature using a questionnaire-the survey distributed to gather the information by asking about their knowledge of awareness regarding the autism environment. The researchers undergo this survey via the electronic study due to the global pandemic covid-19. The survey took about three months for the respondent to respond to the questionnaire. The researchers used the purposive sampling method to choose research participants for this study. Two groups of respondents are closely related to this study. The first group is at the early intervention center, and 30 respondents involved in this study. They are directly involved in the learning space throughout the learning session with these autistic children. The respondent is among the interventionist, occupational therapies, and speech therapies. The second group chosen are among an architect within the technical agency due to their significant role in designing a building. In this survey, the researchers chose approximately 354 architects. They are involved in the planning, designing, and constructing various buildings such as schools, mosques, office buildings, building renovations and more. The data collection carried out during the pandemic covid-19. Therefore, the best method is to contact the respondents through email and an online survey. According to Solans-Domènech et al. (2019), the response rates to postal surveys are low. The researchers contacted the secretariat known as key persons to seek permission to survey to maximize the response rate. Solans-Domènech et al. (2019) suggested that although the response rate was lower than expected, $43 \%$ is within the normal range for online surveys. Hence, out of 384 distributed questionnaires, 174 questionnaires were returned.

Therefore, the research registered a $45.3 \%$ response rate for this survey. The questionnaire comprises four main key concepts: Sensory Sensitivity among the items are sight, sound, smell, taste, touch, proprioception, and Vestibular. Sensory stimulation involving the items acoustic, colour, smell, lighting and visual. Sensory Design among the items is acoustic, spatial sequencing, escape space, compartmentation, transition zone, sensory zoning, safety, and security. Finally, the Physical Learning Environment comprises 
building scale, accessibility, wayfinding, toilet provision, window, ventilation/heating, threshold, legibility, and furniture. In this study, the researcher uses a five-point Likert scale because the only main purpose of applying a Likert Scale is to code the data and present the information consistently easily. Hence, by allocating codes to the responses, a higher score indicates a higher degree of agreement (Pui Teng \& Hassan, 2015).

\subsection{Limitations}

The data collection period occurs during the pandemic Covid-19 and Movement Control Order (MCO) by the government. The researcher used email and online to conduct the survey. However, some respondents are more interested in meeting with researchers while responding to the questionnaire. There is a limitation to approach an expert to validate the questionnaire. There are not many experts in this field. Moreover, the selected expert did not respond and interested in taking part in this validation phase. Therefore, the researcher took quite a long time to get feedback from the expert on whether they are willing to or not interested in this study.

\subsection{Data Preparation and Findings}

Data preparation and cleansing are essential to any research study's quality assurance process (Fleming, 2019). The data analysis using Social Sciences Software (SPSS) version 25 proceeded with examining data entry, reliability and validity has represented the findings' truthfulness (Mohajan, 2017). Cronbach alpha used to determine the reliability of the items tested. The skewness and kurtosis are two important indicators to measure the data normality (Imna \& Hassan, 2015). The researcher using Principle Component Analysis (PCA) to define the construct based on the theoretical framework, which indicates the direction of the measure, identifies the most significant variance in scores with the smallest number of factors and gather information about the interrelationship among a set of variables (Ghorashi et al., 2016; Sakip et al., 2015). The PCA also identifies the dimensionality of items, drop items with low factor loadings, and redundant items from the questionnaires (Hedayati Marzbali et al., 2016).

\subsection{Discussion and Conclusion}

The researcher used varimax rotation and examined the analytic rotation in exploratory factor analysis, finally weighting variables. The final stage for the PCA is naming of factors where it is more of an 'art' as there are no rules for naming factors, except to give names that best represent the factors (Yong \& Pearce, 2013).

The Sensory Sensitivity (SSy) yielded six factors: Proprioception, taste, smell, space, sound, and touch. The first component is proprioception (sense of position). The result expressed by Magda Mostafa (2015) that children with autism commonly have an altered sense of spatial orientation, depth perception and general proprioception that prone to injury. The taste sensation with resulting item support by the study done by K. Gaines et al. (2016) revealed that individuals with autism often have abnormal responses to incoming sensory information from the surrounding environment. The smell sensation demonstrated that autistic senses would trigger and encouraged to respond to their smells (Gaines et al., 2016). The researcher results cast a new labelled space. The results support the previous studies pointed out that minimizing direct lighting, avoiding glare and smooth pathway are all examples of barrier-free design (Hebert, 2003; Gopal \& Raghavan, 2018). The results found clear support for the sound highlight that autism affecting the auditory system (Kinnealey et al., 2012). Without proper sound-proofed, it is an issue for children with autism (Raar, 2012; Block, 2018). The researcher obtains good results labelled touch reasons to touch sensation. Notably, they are more sensitive to touch. This is particularly the sensory sensitivity level is high enough from autistic children requires special handling in the design space (Raar, 2012; Safrilia, 2017).

The Sensory Stimulation (SSn) yielded four components - Smell, Acoustic, Colour and Visual. This study identifies that smell is the most important and the result ties nicely with previous studies wherein Robertson et al. (2012), Safrilia (2017), Block (2018) and Kojovic et al. (2019) reported that unwanted smells difficult to deal with autistic everyday lives. In contrast, essential oils such as chamomile, lavender, geranium, and sandalwood relieve anxiety for autistic (Bonnie Barnes Hebert, 2003). The results found clear support the acoustic is a good choice match the findings by Kanakri (2017) suggested that attention to acoustic design and modifications to existing environments are essential to provides a supportive educational environment. The researcher obtains good results labeled colour, reasons for mood, and stimulating for autistic children (Tuckett et al., 2004; Barrett et al, 2015). The final component for sensory stimulation were labeled as visual. The results lead to a similar conclusion where autistic tend to understand visual stimuli better than audio stimuli compared to normal students (Ahmad et al., 2015). Furthermore, children with autism have strong visual skills and they seem to remember things by their location in space (Bonnie B Hebert, 2003).

The Sensory Design (SD) yielded four components. The result suggests only four components to be considered - spatial, sensory zoning, compartmentation, and safety. The first component is spatial, highlight the fact that noise play an important role in spatial design (Raar, 2012; McLaren \& Page, 2015; Safrilia, 2017; Gopal \& Raghavan, 2018). The researchers illustrated another result labelled as sensory zoning. From the results, it is clear that sensory zoning is important when designing for a group of students with the sensory challenges found predominantly in those with autism (Mostafa, 2014). This may have great impact on the comfort of the user, the conducive quality of the healing and learning environment, as well as the independence enjoyed by autistic as they navigate the space (Mostafa, 2014). The compartmentation is to organize a space to help the autistic to predict the area. The results match the previous study done by Hosny \& Anous (2015) that compartmentalization defines and limits the sensory environment of each activity, organizing a classroom or even an entire building into compartments (Society, 2015; Ghazali, Md Sakip, et al., 2018a). The results of the analysis 
found clear support for the safety component. This is an important and concern for children with autism who may have an altered sense of their environment. As such fittings to protect from hot water and an avoidance of sharp edges and corners are some of these considerations by designers (Mostafa, 2014).

The Physical Learning Environment (PLE) yielded six components - accessibility, furniture, threshold, security, ventilation/heating and building scale. That related the environment that affects children's learning processes, support the well-being and education of children with ASD via the classroom. This analysis found evidence that the component of Physical Learning Environment is the most important to be considered during the design stage and creates a conducive environment for autistic. The accessibility support by previous scholar revealed that the ramps are easier than stairs physically (Tuckett et al., 2004). Further, the concept of accessibility'Universal Design' shall consider presently, where architects should implement its recommendations and building owners are advised to take whatever steps can be 'reasonably' expected to ensure that their buildings are made fully accessible (Tuckett et al., 2004). The furniture delivers significantly better results support by previous study shown that the furniture setting improves the classroom physical environment, especially chairs and tables designed to suit the size of students' (Ramli et al., 2013). The threshold is important for them to allow time and space to prepare for the changes (Ghazali, Md Sakip, et al., 2019). The previous scholar noted that the thresholds help the autistic adjust their senses as they move from one level to the next (Altenmüller-Lewis, 2017; Ghazali, Md Sakip, et al, 2019). The security is important when dealing with autistic who may have difficulty to understand the dangers in the environment (Mcnally et al., 2013; Ghazali, Md Sakip, et al., 2019). For example, to install locks or sensors on any doors, windows, and cabinets as needed, the locks moved higher on doors as well so that they are out of reach (Jones, 2015). The ventilation/heating to be considered by selecting the heating, ventilation, and air conditioning system that may not reduce noise in the learning area (Block, 2018). According to Ghazali et al. (2019), these are the essential features attributes to conducive learning environment. Hence, this can be ultimately help autistic to focus during their learning process, although having different abilities. The researcher obtains good results labelled building scale. The previous study done by Mcnally et al. (2013) support that the scale of a large school can be daunting for a pupil with ASD. Hence, designers are suggested to design and create comfortable in an environment so that they can easily comprehend.

\subsection{Recommendations}

This paper indicates that all key concepts be best measured using PCA - sensory stimulation, sensory sensitivity, sensory design, and physical learning environment are the essential features attributes to a conducive learning environment. The result yielded an interesting component by reducing variables into a smaller set to save time and facilitate easier interpretations (Yong \& Pearce, 2013). Once the validity procedures completed, the researcher suggested performing reliability testing if using factor analysis to validate or construct a questionnaire (Yong \& Pearce, 2013). Reliability refers to a questionnaire's ability to consistently measure an attribute and how well the items fit together, conceptually. Reliability is necessary, is not sufficient to validate an instrument, because an instrument may be reliable but not valid (Parsian et al., 2016). This is important for the researcher to further her analysis for the next action taken.

\section{Acknowledgement}

I would like to thank my supervisor Dr Siti Rasidah Md Sakip and Asso. Prof. Dr Ismail Samsuddin for supporting me. Also, I would thank Jabatan Kerja Raya Malaysia for allowing me to further my study.

\section{Paper Contribution to Related Field of Study}

Since this study was conducted only architect in the government technical agency, further studies among architect in the private sector across the country is recommended. These future studies could also be focused on their knowledge of awareness of sensory issues on designing the autism environment. A better understanding of sensory preferences may enhance creating a conducive learning environment for autistic.

\section{References}

Ahmad, S. S., Shaari, M. F., Hashim, R., \& Kariminia, S. (2015). Conducive Attributes of Physical Learning Environment at Preschool Level for Slow Learners. Procedia - Social and Behavioral Sciences, 201(February), 110-120. https://doi.org/10.1016/j.sbspro.2015.08.138

Altenmüller-Lewis, U. (2017). Designing Schools for Students on the Spectrum. The Design Journal, 20(sup1), S2215-S2229. https://doi.org/10.1080/14606925.2017.1352738

Barrett, P., Davies, F., Zhang, Y., \& Barrett, L. (2015). The impact of classroom design on pupils' learning: Final results ofaholistic, multi-level analysis. Building and Environment, 89, 118-133. https://doi.org/10.1016/j.buildenv.2015.02.013

Beaver, C. (2006). Designing Environments for Children \& Adults with ASD. In Autism Safari 2006 2nd World Autism Congress \& Exhibition.

Block, S. M. (2018). Classroom Design and its Influence on Students 'Performance Within the Autism Spectrum Diagnosis. St. Cloud State University.

Chiam, M. (2016, April 18). Stepping Up. The Star. 
Fleming, S. (2019). Exploring the Experiences of Mature Nursing and Non-Nursing Students' on Fulltime Undergraduate Courses-a Quantitative Study. (Issue March) The University of Dublin]. http://www.tara.tcd.ie/bitstream/handle/2262/86120/Sandra Fleming revised Thesis March 2019 final for pdf.pdf?sequence=5

Gaines, K., Bourne, A., Pearson, M., \& Kleibrink, M. (2016). Designing for Autism Spectrum Disorders. Routledge Taylor \& Francis Group. https://doi.org/10.4324/9781315856872

Ghazali, R., Md. Sakip, S. R., \& Samsuddin, I. (2019). Sensory Design of Learning Environment for Autism : Architects awareness? Journal of ASIAN Behavioural Studies, 4(14), 53-62. https://doi.org/10.21834/jabs.v4i14.338

Ghazali, R., Md Sakip, S. R., \& Samsuddin, I. (2018). A Review of Sensory Design Physical Learning Environment for Autism Centre. E-IPH, AicQoL2018Perhentianlsland, 3(7), 7 pages.

Ghazali, R., Md Sakip, S. R., \& Samsuddin, I. (2019). Creating Positive Environment for Autism Using Sensory Design. Environment-Behaviour Proceedings Journal, 4(10), 19. https://doi.org/10.21834/e-bpj.v4i10.1618

Goodyear, S. (2014). Designing Buildings for Children With Autism. Citylab. https://www.citylab.com/design/2014/04/designing-buildings-children-autism/8960/

Gopal, A., \& Raghavan, J. (2018). Design interventions for Sensory comfort of Autistic children. Autism-Open Access, 08(01), 1-8. https://doi.org/10.4172/21657890.1000227

Hebert, Bonnie B. (2003). Design Guidelines of a Therapeutic Garden for Autistic Children (Issue May). Louisiana State University.

Hedayati Marzbali, M., Abdullah, A., Ignatius, J., \& Maghsoodi Tilaki, M. J. (2016). Examining the effects of crime prevention through environmental design (CPTED) on Residential Burglary. International Journal of Law, Crime and Justice, 46, 86-102. https://doi.org/10.1016/j.jilcj.2016.04.001

Hosny, I., \& Anous, I. (2015). The impact of Interior Design in educational spaces for children with Autism. 90-101.

Imna, M., \& Hassan, Z. (2015). Influence of Human Resource Management Practices on Employee Retention in Maldives Retail Industry. International Journal of Accounting and Business Management, 4(2), 50-80. https://doi.org/10.24924/ijabm/2015.04/v3.iss1/50.80

Jones, L. L. (2015). Life Journey Through Autism : A Guide to Safety.

Kanakri, S. M. (2017a). Spaces Matters : Classroom Acoustics and Repetitive Behaviors in Preschool Children with Autism. American Journal of Pediatrics, 3(6), 89-94. https://doi.org/10.11648/j.ajp.20170306.15

Kinnealey, M., Pfeiffer, B., Miller, J., Roan, C., Shoener, R., \& Ellner, M. L. (2012). Effect of classroom modification on attention and engagement of students with autism or dyspraxia. American Journal of Occupational Therapy, 66(5), 511-519. https://doi.org/10.5014/ajot.2012.004010

Kojovic, Ben Hadid, Franchini, \& Schaer. (2019). Sensory Processing Issues and Their Association with Social Difficulties in Children with Autism Spectrum Disorders. Journal of Clinical Medicine, 8(10), 1508. https://doi.org/10.3390/jcm8101508

Mansor, R. (2016). Majlis Pecah Tanah Program PERMATA Kurnia. In Permata Kurnia. http://www.programpermata.my/en/patron/speeches/2013/majlis-pecah-tanahprogram-permata-kurnia/

Martin, C. S. (2014). Exploring the impact of the design of the physical classroom environment on young children with autism spectrum disorder (ASD). Journal of Research in Special Educational Needs, 16(4), 19 pages. https://doi.org/10.1111/1471-3802.12092

Martins, R., Bonito, I., Andrade, A., Albuquerque, C., \& Chaves, C. (2015). The Impact of the Diagnosis of Autism in Parents of Children. Procedia - Social and Behavioral Sciences, 171, 121-125. https://doi.org/10.1016/j.sbspro.2015.01.097

McLaren, S., \& Page, W. (2015). Noise and the Implications for Children with Autism Spectrum Disorder in Mainstream Education. Autin Journal of Neurological Disorders \& Epilepsy, 2(1), 6 pages

Mcnally, H., Morris, D., \& Mcallister, K. (2013). Experiencing Primary School through the lens of the autistic spectrum. Aldo goes to Primary School (D. M. \& K. M. A Hugh McNally (ed.)). McNally Morris Architects

Mohajan, H. K. (2017). Two Criteria for Good Measurements in Research: Validity and Reliability. Annals of Spiru Haret University. Economic Series, 17(4), 59-82. https://doi.org/10.26458/1746

Mostafa, M. (2014). Architecture For Autism: Autism ASPECTSS?? in School Design. International Journal of Architectural Research-Archnet-IJAR, 8(1), 143-158.

Mostafa, M. (2015). An Architecture for Autism: Built Environment Performance in Accordance to the Autism ASPECTSSTM Design Index. Design Principles and Practices: An International Journal-Annual Review, 8(1), 55-71. https://doi.org/10.18848/1833-1874/cgp/v08/38300

Nazri, N. A., \& Ismail, Z. (2016). Educational building facilities for children with autism in Malaysia. Jurnal Teknologi. https://doi.org/10.11113/jt.v78.8489 Osci, Y. (2014). Exploring Sensory Design

Parsian, N., Ghorashi, Z., yousefy, A., \& merghati-khoei, E. (2016). Developing and validating a questionnaire to measure women's sexual behaviors: A psychometric process. Galen Medical Journal, 1(1), 208-214

Pui Teng, W., \& Hassan, Z. (2015). The Influence of Transformational Leadership in Creating a Learning Organisation. International Journal of Accounting and Business Management, 3(1), 162-186. https://doi.org/10.24924/ijabm/2015.04/v3.iss1/162.186

Raar, E. (2012). Sensitive Design. 192 
Ramli, N. H., Ahmad, S., \& Masri, M. H. (2013). Improving the Classroom Physical Environment: Classroom Users' Perception. Procedia - Social and Behavioral Sciences, 101, 221-229. https://doi.org/10.1016/j.sbspro.2013.07.195

Razak, N. (2014). The International Seminar on Autism Malaysia. In Pusat Permata Kurnia (Issue April). http://www.programpermata.my/en/patron/speeches/2014/theinternational-seminar-on-autism-malaysia-2014/

Robertson, A. E., Sc, M., \& Hons, M. A. (2012). Sensory Experiences of Individuals with Autism Spectrum Disorder and Autistic Traits : A Mixed Methods Approach. University of Glasgow.

Safrilia, A. (2017). Sensory Design : Hypersensitive and Hyposensitive Autism Rehabilitation Center in Malang. 6(01), 306-311.

Sakip, S. R. M., Hassan, K., \& Mansor, A. (2015). Exploring the Relationship between Community Happiness and Environmental Setting. Postgradutate Conference on Global Green Issues (Go Green), OCTOBER, 425-432.

Samadi, S. A., \& McConkey, R. (2011). Autism in Developing Countries: Lessons from Iran. Autism Research and Treatment, 2011(August), 1-11. https://doi.org/10.1155/2011/145359

Scott, I. (2009). Designing learning spaces for children on the autism spectrum. Good Autism Practices, (10)1(1), 36-51.

http://www.research.ed.ac.uk/portal/en/publications/designing-learning-spaces-for-children-on-the-autism-spectrum(5e79c41d-b247-4eae-8474-db297b91d05f).html

Shaari, M. F., \& Ahmad, S. S. (2016). Physical Learning Environment: Impact on Children School Readiness in Malaysian Preschools. Procedia - Social and Behavioral Sciences, 222, 9-18. https://doi.org/10.1016/j.sbspro.2016.05.164

Solans-Domènech, M., MV Pons, J., Adam, P., Grau, J., \& Aymerich, M. (2019). Development and validation of a questionnaire to measure research impact. Research Evaluation, 28(3), 253-262. https://doi.org/10.1093/reseval/rvz007

Tuckett, P., Marchant, R., \& Jones, M. (2004). Cognitive impairment, access and the built environment. March.

Yong, A. G., \& Pearce, S. (2013). A Beginner's Guide to Factor Analysis: Focusing on Exploratory Factor Analysis. Tutorials in Quantitative Methods for Psychology, 9(2), 79-94. https://doi.org/10.20982/tqmp.09.2.p079

Zuljadan, M. A. (2017). Kempen Sokong Usaha Bantu Kanak-Kanak Autisme. Harian Metro. https://www.hmetro.com.my/node/224532, 12 January 2018 